\title{
Analysis of American Medical Students' Knowledge of Physical Activity Recommendations
}

Candace A. Adedokun, MD | Wesley G. Curles, BS | Emily L. DeMaio, MD | Irfan M. Asif, MD PRiMER. 2021;5:31.

Published: 9/16/2021 | DOI: 10.22454/PRiMER.2021.249084

\section{Abstract}

Introduction: The benefits of physical activity (PA) are widely recognized; American medical schools have begun to emphasize PA, but the effectiveness of these changes is unclear.

Methods: We performed a cross-sectional analysis of medical students enrolled in US osteopathic and allopathic medical schools between August 2019 and May 2020. All participants completed an electronic survey about PA instruction across the 4 years of medical school. Objective information including hours and format of PA instruction was collected. Subjectively, participants reported their relative comfort discussing various aspects of PA education with patients.

Results: A total of 480 medical students completed the survey, representing 82 of the 192 US medical schools (69 allopathic, 13 osteopathic). Students are more comfortable discussing overall exercise benefits than exercise testing, exercise prescription, and exercise physiology $(P<.0001)$. They also report more exposure to general PA guidelines related to overall PA duration than strength training $(P<.0001)$. Students at allopathic and osteopathic schools reported similar outcomes regarding PA education, while students with class sizes under 200 reported increased familiarity with National Physical Activity Guidelines regarding PA duration $(P<.0001)$ and strength training $(P=.01)$.

Conclusion: Despite recent efforts to improve PA education in medical school, students feel unprepared to apply their knowledge in a clinical setting and remain unaware of national PA guidelines. Future studies should determine how to practically integrate PA education longitudinally into curricula to change PA education from an afterthought to an essential component of medical school education.

\section{Introduction}

The overall health benefits of physical activity (PA) are wide ranging, cost effective, and universally recognized. ${ }^{1-22}$ Incoming medical students understand the importance of $P A$, as more than $97 \%$ of them report moderate or vigorous personal exercise programs. ${ }^{23}$ However, traditional medical education focuses on pharmacologic management of chronic diseases, failing to emphasize prevention. ${ }^{9,20,23,24}$ Consequently, the majority of future physicians are uncomfortable discussing the details of PA with their patients. ${ }^{25-28}$

Although many American medical schools have expanded their PA education, ${ }^{21,29-32}$ few studies have examined the results of these curriculum modifications. ${ }^{4,21,33-36}$ Understanding the knowledge and comfort 
level of future physicians is essential for targeted, effective curricular changes. We sought to analyze medical students' perspectives of the quantity and quality of PA education received during medical school and to assess comfort with discussing aspects of PA with patients, specifically the National Physical Activity Guidelines. $^{37}$

\section{Methods}

We conducted a cross-sectional analysis of medical students of all class years enrolled in osteopathic and allopathic medical schools in the United States with Institutional Review Board (IRB) approval. From August 2019 to May 2020, a 19-question electronic survey created via Research Electronic Data Capture (REDCap, Vanderbilt University, Nashville, TN) was distributed via email to medical student members of the American Medical Society of Sports Medicine (AMSSM, Appendix A). The survey was anonymous, and no incentive was provided for completion. The initial response rate was low (14 completed surveys from 330 email addresses), and the authors began distributing the survey to more targeted audiences. The survey was emailed to the primary contact of the AMSSM Charter Medical Schools to circulate to students at their individual medical school. The authors also distributed the survey link to medical students at their respective institutions and via social media (Facebook and GroupMe). We collected objective information, including hours and format of PA instruction, and subjective opinions of comfort with PA education.

We calculated descriptive statistics for categorical and continuous variables. Tests of significance utilized included $\chi^{2}$, Fisher's exact, Student $t$ tests, and Mann-Whitney $U$ tests, where appropriate. $P$ values less than .05 were considered statistically significant. We performed all analyses with SAS (SAS Institute, Cary, NC).

\section{Results}

A total of 480 medical students completed the survey, representing 82 US medical schools (69 allopathic, 13 osteopathic, Appendix B). The largest cohort of respondents were third-year students (33.5\%). Further demographics can be found in Table 1. Instructional delivery of PA content varied by class year, but $71 \%$ of respondents reported at least one instance of exercise-related didactic instruction (Table 2).

Medical students receive more exercise-related instruction in their preclinical years (mean=7.84 hrs) than their clinical years (mean=3.96 hrs, $P<.0001$ ), with the majority taking place in their first year (mean \pm standard deviation: $4.31 \pm 7.02$ hours, Table 2). Respondents reported a total of 11.82 total hours dedicated to PA over the 4 years of medical school.

Most students (89.6\%) report that they would be comfortable discussing the overall health benefits of exercise with a patient. However, students are less familiar with details of exercise testing, prescription, and physiology, and they are less confident in their ability to discuss these topics with patients $(P<.0001$, Table 3$)$. Only $27.1 \%$ of fourth-year medical students believe they would be able to prescribe an appropriate fitness plan for a patient. Medical students reported more exposure to PA guidelines related to overall PA duration (63.1\%) than strength training $(43.4 \%, P<.0001$, Table 4$)$.

There was no significant difference between allopathic and osteopathic schools regarding familiarity with guidelines on exercise duration $(P=.23)$ and strength training $(P=.70)$. Respondents attending institutions with class sizes under 200 reported increased familiarity with National Physical Activity Guidelines regarding PA duration $(P<.0001)$ and strength training $(P=.01)$ relative to those at larger institutions.

\section{Conclusions}


Medical students in this sample received more PA instruction in their preclinical years than their clinical years. Although $63.1 \%$ of respondents were aware of national recommendations on aerobic exercise, only $43.3 \%$ were familiar with strength training guidelines. Additionally, our findings illustrate that despite student comfort with discussing the general benefits of PA, their ability to provide specific exercise instruction is relatively limited.

Dacey et al published the lone systematic review examining PA instruction in medical school education, reporting widespread didactic instruction and minimal clinical application. ${ }^{38}$ Our findings mirror Dacey's; students received extensive didactic instruction in PA, but only $24.6 \%$ of them reported clinical application of that knowledge.

This study inherently has limitations. Given the lack of incentivization, students interested in PA may have been more likely to respond, contributing to response bias. These students are also more likely to seek out PA educational opportunities and may disproportionately recall teaching related to PA. Therefore, results may not be representative of the average medical student. The means of survey dissemination resulted in higher responses from certain medical schools, thereby reducing generalizability. The study could have been strengthened by weighting responses, but we were unable to do so given the large number of schools with few respondents. Recall bias was intrinsically present because respondents were asked to report education that occurred years prior. Additionally, as most students completed this survey in February and March, they likely underestimated the number of hours of PA education in their current year of school. While our assessment of medical student comfort was binary, future investigation should utilize a Likert scale to more adequately describe comfort in discussing PA with patients.

In summary, we observed that medical students receive minimal education on PA, resulting in low comfort in discussing PA with patients. Future studies should objectively examine the ability of medical school graduates to assess exercise needs and appropriately counsel patients on PA programs. That data, when combined with curriculum analysis, would compare the effectiveness of instructional methods employed by schools across the country. Regardless of the next step in research, it is imperative that PA education evolves from an afterthought to an essential component of medical education.

\section{Tables and Figures}


Table 1: Individual and Institutional Demographics of Survey Respondents

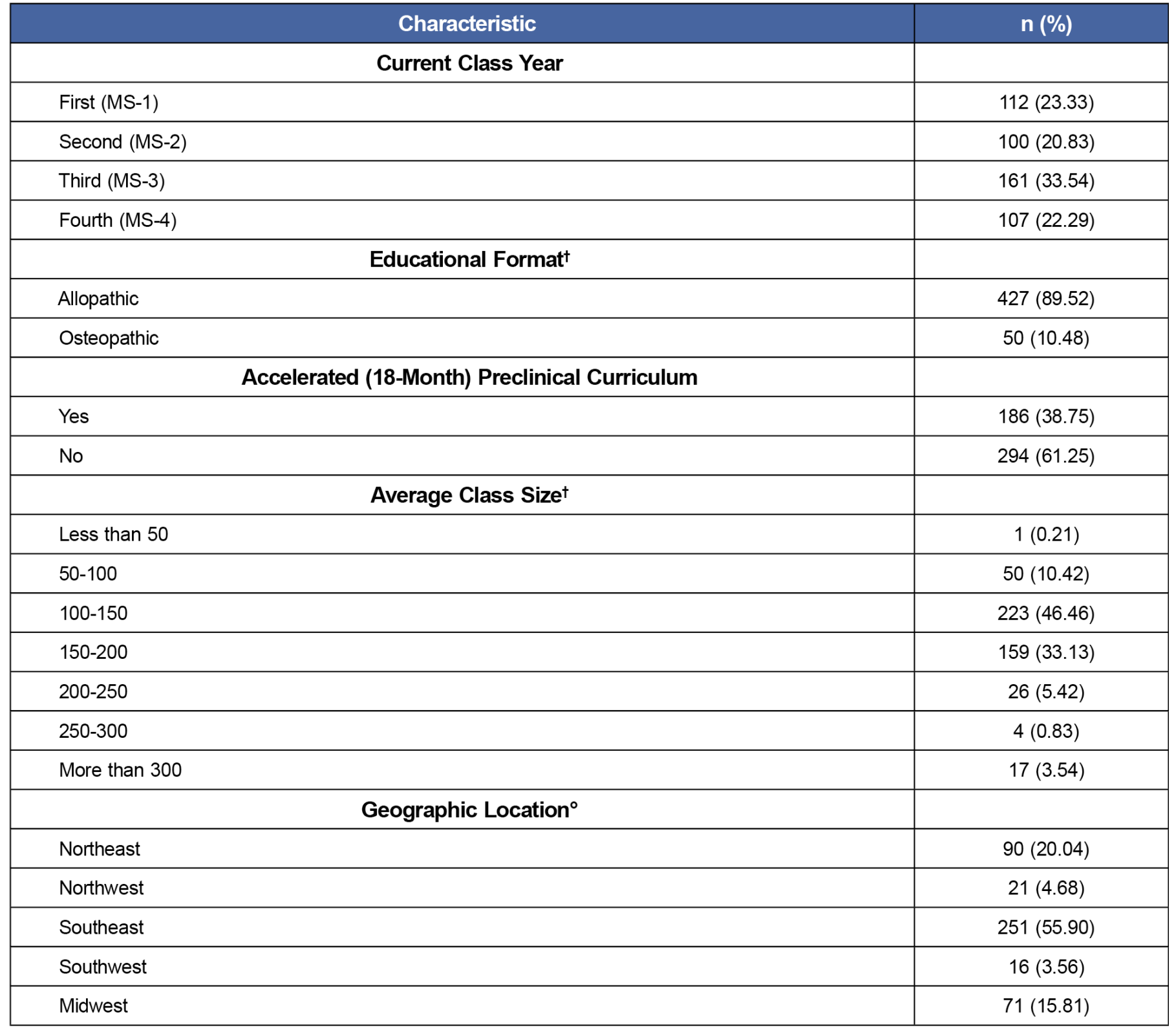

$\dagger=$ "| don't know" option included in survey but not represented in table;

${ }^{\circ}=$ Regional distinctions/boundaries left to the discretion of survey respondents, "Other" option included in survey but not represented in table. 
Table 2: Characteristics of PA Instruction by Respondent Class Year

\begin{tabular}{|c|c|c|c|c|}
\hline & $\begin{array}{l}\text { First Year } \\
(\mathrm{N}=480)\end{array}$ & $\begin{array}{l}\text { Second Year } \\
\qquad(N=368)\end{array}$ & $\begin{array}{l}\text { Third Year } \\
(N=268)\end{array}$ & $\begin{array}{l}\text { Fourth Year } \\
\qquad(N=107)\end{array}$ \\
\hline Total Hours (Average $\pm S D$ ) & $4.31 \pm 7.02$ & $3.54 \pm 8.04$ & $2.96 \pm 9.28$ & $1.01 \pm 3.27$ \\
\hline Didactics & 71.7 & 42.5 & 14.0 & 4.8 \\
\hline Clinical experiences & 18.3 & 12.1 & 24.6 & 8.8 \\
\hline OSCE/clinical examination & 20.4 & 18.3 & 11.5 & 2.9 \\
\hline Case-based instruction & 27.1 & 20 & 9.80 & 2.7 \\
\hline Motivational techniques & 35.8 & 20 & 13.1 & 2.7 \\
\hline
\end{tabular}

Abbreviations: PA, physical activity; SD, standard deviation; OSCE, objective structured clinical examination.

$\%=$ Percentage of students who report receiving this specific mode of instruction during the given academic year.

Table 3: Respondent Comfort Discussing Each Characteristic of PA With Patients

\begin{tabular}{|l|c|}
\hline \multicolumn{1}{|c|}{ Characteristic } & $\mathrm{n}(\%)$ \\
\hline Benefits of physical activity & $430(89.58)$ \\
\hline Exercise testing & $206(42.92)$ \\
\hline Exercise prescription & $157(32.71)$ \\
\hline Exercise nutrition & $156(32.50)$ \\
\hline Exercise physiology & $185(38.54)$ \\
\hline Max HR/Aerobic HR training zones & $127(26.46)$ \\
\hline Exercise and behavior change & $243(50.63)$ \\
\hline None of the above & $35(7.29)$ \\
\hline
\end{tabular}

Abbreviations: PA, physical activity; HR, heart rate.

Exercise testing was defined to include treadmill testing or cardiopulmonary exercise testing with VO max. Exercise prescription was defined as a specific plan of fitness related activities that are designed for a specified purpose. Exercise and behavior change was defined as motivational interviewing techniques, such as the Prochaska Model of Change.

Table 4: Respondent Knowledge of 2018 National PA Guidelines ${ }^{38}$

\begin{tabular}{|l|r|}
\hline \multicolumn{1}{|c|}{ Characteristic } & $\mathrm{n}(\%)$ \\
\hline Yes 150 Minutes/Week of Moderate to Vigorous Aerobic Activity & $303(63.13)$ \\
\hline No & $177(36.88)$ \\
\hline Strength Training Twice/Week & $208(43.33)$ \\
\hline No & $272(56.67)$ \\
\hline
\end{tabular}

Abbreviation: PA, physical activity. 


\section{Acknowledgments}

The authors are grateful for the expertise of Gerald McGwin, PhD, MS, who assisted with statistical analysis. They thank their colleagues in the UAB Office of Clinical Research, especially Debbie Lowman, MA, for their assistance in study design and execution.

\section{Corresponding Author}

Irfan M. Asif, MD

University of Alabama at Birmingham (UAB) Department of Family \& Community Medicine, 930 20th Street South, Birmingham, AL 35205. 205-934- 9700. Fax: 205-975- 6962.

imasif@uab.edu

\section{Author Affiliations}

Candace A. Adedokun, MD - Saint Louis University Department of Family and Community Medicine Wesley G. Curles, BS - University of Alabama at Birmingham (UAB) Department of Family \& Community Medicine

Emily L. DeMaio, MD - McGaw Medical Center of Northwestern University Department of Orthopaedic Surgery Irfan M. Asif, MD - Department of Family and Community Medicine, University of Alabama-Birmingham School of Medicine

\section{References}

1. Oster G, Edelsberg J, O'Sullivan AK, Thompson D. The clinical and economic burden of obesity in a managed care setting. Am J Manag Care. 2000;6(6):681-689.

2. Flegal KM, Carroll MD, Kit BK, Ogden CL. Prevalence of obesity and trends in the distribution of body mass index among US adults, 1999-2010. JAMA. 2012;307(5):491-497. doi:10.1001/jama.2012.39

3. Clarke CA, Bonnet JP, Gail Davis M, Frates EP. Lifestyle medicine professionals in training: a survey of behaviors, knowledge and needs. Internet J Allied Health Sci Pract. 2017;15(4):11.

4. Center BP. Teaching nutrition and physical activity in medical school: training doctors for prevention oriented care. Wahington, DC: Bipartisan Policy Center; 2014.

5. Craft LL, Perna FM. The Benefits of Exercise for the Clinically Depressed. Prim Care Companion J Clin Psychiatry. 2004;6(3):104-111. doi:10.4088/PCC.v06n0301

6. Vina J, Sanchis-Gomar F, Martinez-Bello V, Gomez-Cabrera MC. Exercise acts as a drug; the pharmacological benefits of exercise. Br J Pharmacol. 2012;167(1):1-12.

doi:10.1111/j.1476-5381.2012.01970.x

7. Fentem $\mathrm{PH}$. ABC of sports medicine. Benefits of exercise in health and disease. BMJ. 1994;308(6939):1291-1295. doi:10.1136/bmj.308.6939.1291

8. Agarwal SK. Cardiovascular benefits of exercise. Int J Gen Med. 2012;5:541-545. doi:10.2147/IJGM.S30113

9. Ruby MB, Dunn EW, Perrino A, Gillis R, Viel S. The invisible benefits of exercise. Health Psychol. 2011;30(1):67-74. doi:10.1037/a0021859

10. Praet SF, van Loon LJ. Optimizing the therapeutic benefits of exercise in Type 2 diabetes. J Appl Physiol (1985). 2007;103(4):1113-1120.

11. Holtz KA, Kokotilo KJ, Fitzgerald BE, Frank E. Exercise behaviour and attitudes among fourth-year medical students at the University of British Columbia. Can Fam Physician. 2013;59(1):e26-e32.

12. Grant RW, Schmittdiel JA, Neugebauer RS, Uratsu CS, Sternfeld B. Exercise as a vital sign: a quasiexperimental analysis of a health system intervention to collect patient-reported exercise levels. J Gen 
Intern Med. 2014;29(2):341-348. doi:10.1007/s11606-013-2693-9

13. Huang J, Yu H, Marin E, Brock S, Carden D, Davis T. Physicians' weight loss counseling in two public hospital primary care clinics. Acad Med. 2004;79(2):156-161. doi:10.1097/00001888-200402000-00012

14. Noormohammadpour P, Halabchi F, Mazaheri R, et al. Designing and implementing a curriculum for Sports and Exercise Medicine elective course for undergraduate medical students of Tehran University of Medical Sciences. Br J Sports Med. 2019;53(10):601-604. doi:10.1136/bjsports-2018-099462

15. Angyán L. Promoting physical activity in medical education. Mini-review. Acta Physiol Hung. 2004;91(2):157-166. doi:10.1556/APhysiol.91.2004.2.7

16. Block JP, DeSalvo KB, Fisher WP. Are physicians equipped to address the obesity epidemic? Knowledge and attitudes of internal medicine residents. Prev Med. 2003;36(6):669-675. doi:10.1016/S0091-7435(03)00055-0

17. Park EA. National Review of US Medical Education Curricula for Physical Activity-Related Content. 2014.

18. Barnes PM, Schoenborn CA. Trends in adults receiving a recommendation for exercise or other physical activity from a physician or other health professional. NCHS Data Brief. 2012;(86):1-8.

19. Stoutenberg M, Stasi S, Stamatakis E, et al. Physical activity training in US medical schools: preparing future physicians to engage in primary prevention. Phys Sportsmed. 2015;43(4):388-394. doi:10.1080/00913847.2015.1084868

20. Garry JP, Diamond JJ, Whitley TW. Physical activity curricula in medical schools. Acad Med. 2002;77(8):818-820. doi:10.1097/00001888-200208000-00011

21. Trilk JL, Phillips EM. Incorporating 'Exercise is Medicine' into the University of South Carolina School of Medicine Greenville and Greenville Health System. Br J Sports Med. 2014;48(3):165-167. doi:10.1136/bjsports-2013-093157

22. Lee IM, Shiroma EJ, Lobelo F, Puska P, Blair SN, Katzmarzyk PT; Lancet Physical Activity Series Working Group. Effect of physical inactivity on major non-communicable diseases worldwide: an analysis of burden of disease and life expectancy. Lancet. 2012;380(9838):219-229. doi:10.1016/S0140-6736(12)61031-9

23. Denyer Willis L, Chandler C. Quick fix for care, productivity, hygiene and inequality: reframing the entrenched problem of antibiotic overuse. BMJ Glob Health. 2019;4(4):e001590. doi:10.1136/bmjgh2019-001590

24. Frank E, Carrera JS, Elon L, Hertzberg VS. Predictors of US medical students' prevention counseling practices. Prev Med. 2007;44(1):76-81. doi:10.1016/j.ypmed.2006.07.018

25. Rogers LQ, Bailey JE, Gutin B, et al. Teaching resident physicians to provide exercise counseling: a needs assessment. Acad Med. 2002;77(8):841-844. doi:10.1097/00001888-200208000-00019

26. Rogers LQ, Gutin B, Humphries MC, et al. Evaluation of internal medicine residents as exercise role models and associations with self-reported counseling behavior, confidence, and perceived success. Teach Learn Med. 2006;18(3):215-221. doi:10.1207/s15328015tIm1803_5

27. Solmundson K, Koehle M, McKenzie D. Are we adequately preparing the next generation of physicians to prescribe exercise as prevention and treatment? Residents express the desire for more training in exercise prescription. Can Med Educ J. 2016;7(2):e79-e96. doi:10.36834/cmej.36702

28. Vallance JK, Wylie M, MacDonald R. Medical students' self-perceived competence and prescription of patient-centered physical activity. Prev Med. 2009;48(2):164-166. doi:10.1016/j.ypmed.2008.12.006

29. Cardinal BJ, Park EA, Kim M, Cardinal MK. If Exercise is Medicine, Where is Exercise in Medicine? Review of U.S. Medical Education Curricula for Physical Activity-Related Content. J Phys Act Health. 2015;12(9):1336-1343. doi:10.1123/jpah.2014-0316

30. Hudson JN, Farmer EA, Weston KM, Bushnell JA. Using a framework to implement large-scale innovation in medical education with the intent of achieving sustainability. BMC Med Educ. 2015;15(1):2. doi:10.1186/s12909-014-0282-1

31. Pandya T, Marino K. Embedding sports and exercise medicine into the medical curriculum; a call for 
inclusion. BMC Med Educ. 2018;18(1):306. doi:10.1186/s12909-018-1422-9

32. Youkey JR, Trilk JL. Incorporating emerging fields in medical education. Clin Teach. 2018;15(3):265-267. doi:10.1111/tct.12723

33. Polak R, Finkelstein A, Axelrod T, et al. Medical students as health coaches: implementation of a studentinitiated Lifestyle Medicine curriculum. Isr J Health Policy Res. 2017;6(1):42-42. doi:10.1186/s13584-017-0167-y

34. Taylor WC, Moore GT. Health promotion and disease prevention: integration into a medical school curriculum. Med Educ. 1994;28(6):481-487. doi:10.1111/j.1365-2923.1994.tb02723.x

35. Pojednic R, Frates E. A parallel curriculum in lifestyle medicine. Clin Teach. 2017;14(1):27-31. doi:10.1111/tct.12475

36. Wagner PJ, Jester DM, Moseley GC. Medical students as health coaches. Acad Med. 2002;77(11):1164-1165.

37. Services USDoHaH. Physical Activity Guidelines for Americans. 2nd ed. 2018.

38. Dacey ML, Kennedy MA, Polak R, Phillips EM. Physical activity counseling in medical school education: a systematic review. Med Educ Online. 2014;19(1):24325. doi:10.3402/meo.v19.24325

Copyright $\odot 2021$ by the Society of Teachers of Family Medicine 